Ольга Кулагина

ORCID: 0000-0002-7382-4751

Московский педагогический государственный университет

Москва, Россия

\title{
Мужские персонажи в творчестве Жака Превера и их языковая репрезентация
}

https://doi.org/10.34739/clit.2021.15.13

\author{
Male Characters in Jacques Prévert's Works \\ and Their Linguistic Representation
}

The article examines the main groups of male characters in the poetic texts of Jacques Prévert. In the process of analysis, three hypostases are distinguished: a father, a man in love / a beloved man, and a non-human being endowed with masculine features. For each of these categories, we consider the main linguistic means of their representation, first of all, at the level of stylistics and grammar.

Keywords: male characters. Jacques Prévert, linguistic means

В произведениях французского поэта Жака Превера наиболее яркими и рельефными являются, на первый взгляд, женские персонажи, как проявленные, так и скрытые. Однако, мужские образы представляются не менее значимыми для понимания творчества Превера. В своей статье мы ставим перед собой цель выявить основные языковые средства изображения персонажей-мужчин в таких стихотворных сборниках Превера, как Choses et autres (Одно u другое), Fatras (Всякий хлам), Histoires et d'autres histoires (Истории и ещё истории), La pluie et le beau teтps (Дождь и вёдро) и Paroles (Слова). Для этого мы выделили несколько разновидностей ролей, в которых выступают мужские персонажи у Превера и которые мы рассмотрим ниже.

\section{1. Роль отца}

Фигура отца в творчестве Превера может совмещать в себе как отцовские, так и материнские функции, но эта амбивалентность словно 
обесценивается - как самим автором, так и другими персонажами. В качестве примера приведём стихотворение $A$ l'improviste (Внезапно):

Moi aussi je suis le fils de l'homme quand je suis né ma mère n'était pas là

Où était-elle?

Au marché peut-être ou chez les voisins pour leur emprunter du pain et du vin

En son absence mon père a fait l'impossible pour faire le nécessaire et il a paraît-il beaucoup souffert Mais qu'est-ce que ça peut faire Tant de gens avant lui et depuis ont souffert sous Ponce Pilate Napoléon Bonaparte César Borgia Salazar Franco Staline Luther ou Adolf Hitler ${ }^{1}$

Я тоже сын человеческий и сын мужчины родился я, когда моей матери не было рядом Где же она была? Наверное, на рынке или у соседей, у которых просила в долг хлеба и вина В её отсутствие мой отец сделал невозможное чтобы сделать необходимое и вроде бы он сильно мучился Но что с того Столько народу мучилось до и после него при

Понтии Пилате, Наполеоне Бонапарте, Чезаре Борджиа, Салазаре, Франко, Сталине, Лютере или Адольфе Гитлере ${ }^{2}$

В приведённом примере стоит отметить омонимию слов «человек» и «мужчина», которые во французском языке передаются лексемой «homme», что создаёт, с одной стороны, библейскую аллюзию (усиленную за счёт упоминания о хлебе и вине - атрибутах христианского таинства причастия), а с другой, словно нивелирует мужественность отца лирического героя. Әффект нивелирования обеспечивается также за счёт парадокса «quand je suis né ma mère n'était pas là» («родился я, когда моей матери не было рядом») и параллелизма «mon père a fait l'impossible pour faire le nécessaire» («мой отец сделал невозможное, чтобы сделать необходимое»), где

${ }^{1}$ J. Prévert, Choses et autres, Paris 2011, p. 70.

2 Здесь и далее перевод наш - О.К. 
гиперболизированное действие отца низводится до некоего повседневного уровня. Окончательная девальвация отцовского подвига показана посредством повтора глагола «souffrir» («мучиться») в разных контекстах: вначале - применительно к конкретному человеку, а именно, отцу героя; затем - в отношении всего человечества. Данный повтор передаёт ничтожность страданий отдельно взятого человека по сравнению с бедствиями, причинёнными миру по вине авторитарных режимов либо религиозных реформ (последний факт представляется значимым в данном контексте, поскольку Превер отличался активной антиклерикальной позицией, которая нашла отражение в значительной части его текстов). Таким образом, фигура отца и его неординарный поступок оказываются обесценены в масштабах общечеловеческих проблем.

Если в рассмотренном примере персонаж отца подвергается незаслуженному моральному унижению со стороны сына, то в стихотворении Drôle dimmeuble (Странный дом) показано отцеубийство как месть за дурное обращение. Приведём фрагмент стихотворения:

Au quatrième sur la cour un enfant joue avec des allumettes et il met le feu à son père Un peu plus tard la mère arrive Ça sent le caoutchouc grillé qu'est-ce que tu as encore fait C'est rien

les bretelles à papa

Où est-il ton père

Je ne sais pas maman je ne sais pas

La mère cherche et l'enfant fait semblant de chercher Brave petit coeur Soudain la mère voit le cendrier plein C'est fou ce que cet homme peut fumer ça coûte cher et ça ne sert à rien Elle prend le cendrier et dans la cuisine l'enfant la suit Cendrier vidé dans la poubelle délicieuse petite aquarelle 
liquidation du paternel

Paix à ses cendres dit l'enfant

il me battait 3

На четвёртом этаже, с видом на двор

ребёнок играет со спичками

и поджигает своего отца

Немного погодя приходит мать

Пахнет жжёной резиной

что ты опять натворил?

Да так, ничего

это папины помочи

Где твой отец?

Не знаю, мамочка, не знаю

Мать ищет

и ребёнок делает вид, что тоже ищет

Славный малыш

Вдруг мать замечает полную пепельницу

С ума сойти, сколько же этот человек курит

это так дорого стоит, а пользы никакой

Она берёт пепельницу

и ребёнок идёт за ней на кухню

Пепел вытряхнут в мусорное ведро

восхитительное полотно акварелью

ликвидация всего отцовского

Мир его праху, говорит ребёнок

он меня бил

В данном примере персонаж отца не просто уничтожается физически, но ещё и подвергается уничижению со стороны своей жены, которая называет его исключительно посредством перифраз «ton père» («твой отец») и «cet homme» («этот человек»). Обращает на себя внимание и тот факт, что ребёнок в стихотворении - также мужского пола (такой вывод можно сделать за счёт обозначения этого персонажа местоимением «il» - «он»). Но, если его отец, судя по всему, склонен к прямому насилию (что показано употреблением глагола «battre» - «бить»), то сам ребёнок действует скрытно, сохраняя видимость пристойного поведения, что демонстрируется метафорическим антифразисом «Brave petit coeur» («славный

3 J. Prévert, La pluie et le beau temps, Paris 2011, p. 111-112. 
малыш») и метафорой «Paix à ses cendres» («мир его праху»), которые позволяют говорить о скрытности и лицемерии ребёнка-отцеубийцы.

\section{2. Роль влюблённого / любимого мужчины}

Влюблённый мужчина в творчестве Превера - персонаж довольно неоднозначный. С одной стороны, он может выступать как тюремщик для своей возлюбленной, но тюремщик, как правило, незадачливый. Приведём фрагмент хрестоматийного стихотворения Pour toi, mon amour (Для тебя, моя любовь):

Je suis allé au marché à la ferraille

Et j'ai acheté des chaînes

De lourdes chaînes

Pour toi

mon amour

Et puis je suis allé au marché aux esclaves

Et je t'ai cherchée

Mais je ne t'ai pas trouvée

mon amour 4

Я пошёл на рынок металлолома

И купил цепи

Тяжёлые цепи

Для тебя

моя любовь

А потом я пошёл на невольничий рынок

И стал искать там тебя

Но я тебя там не нашёл

моя любовь

В приведённом примере обращает на себя внимание контраст целой серии действий, обозначенных глаголом в утвердительной форме, и единственного глагола в отрицательной форме, который показывает самое главное действие (вернее, отсутствие действия), которое обесценивает все усилия героя по подготовке «тюрьмы» для своей любимой (подчеркнём, что грамматический аспект анализа текстов Превера представляется нам значимым, поскольку грамматика текста представляет собой весьма существенный аспект

4 J. Prévert, Paroles, Paris 2011, p. 46. 
риторики ${ }^{5}$ а тексты Превера легко распадаются на элементы фраз и элементы слова $\left.{ }^{6}\right)$. В то же время, герои Превера могут выступать и как «гуманные» тюремщики, готовые дать возлюбленной свободу. В подтверждение этой мысли приведём отрывок из стихотворения Chanson du geôlier (Песня тюремщика):

Où vas-tu beau geôlier

Avec cette clé tâchée de sang

Je vais délivrer celle que j’aime

S'il en est encore temps

Et que j’ai enfermée

Tendrement cruellement

Au plus secret de mon désir

Au plus profond de mon tourment

Dans les mensonges de l'avenir

Dans les bêtises des serments7

Куда ты идёшь, прекрасный тюремщик

С этим ключом, запачканным кровью?

Я иду освободить ту, которую люблю

Если успею

Ту, которую я запер

Нежно, жестоко

В самой большой тайне своего желания

В самой глубине своего мучения

Во лжи будущего

В глупостях клятв

Сразу обращает на себя внимание упоминание об окровавленном ключе - отсылка к сказке Ш. Перро Синяя Борода, где ключ, запачканный кровью, становится уликой против героини, нарушившей запрет входить в потайную комнату. В стихотворении Превера такой ключ - символ принятого героем решения собственноручно открыть свою «потайную комнату» и выпустить пленницу на волю. Сама «тюрьма» показана посредством серии метафор «Au plus secret de mon désir / Au plus profond de mon tourment

5 Ю. Лотман, Риторика, [в:] Статьи по семиотике и топологии культуры. https://www.gumer.info/bibliotek_Buks/Culture/Lotm/index.php [дата доступа: 01.11.2020].

6 Т. Хмельницкая, Жак Превер (род. в 1900 г.). Кровь и птицы, http://17v-eurolit.niv.ru/17v-euro-lit/pisateli-francii/zhak-prever.htm [дата доступа: 21.04.2021].

7 J. Prévert, Paroles..., op. cit., p. 195. 
/ Dans les mensonges de l'avenir / Dans les bêtises des serments» («В самой большой тайне своего желания / В самой глубине своего мучения / Во лжи будущего / В глупостях клятв»), где преобладают лексемы с негативной коннотацией («tourment - мучение», «mensonges ложь», «bêtises - глупости»), показывая раскаяние героя в совершённом поступке. Любовный «плен» также обозначается эпитетами «tendrement cruellement» («нежно, жестоко»), сочетание которых производит эффект парадокса. Тем не менее, глагол «délivrer» («освободить»), с которого начинается стихотворение, словно перечёркивает всё развёрнутое описание «заключения», которому подверглась возлюбленная героя, и вступает в противоборство с глаголом «enfermer» («запереть»). Тем не менее, отпуская возлюбленную, герой всё же не готов расстаться с ней совсем:

Et si je reste seul

Et elle en allée

Je garderai seulement

Je garderai toujours

Dans mes deux mains en creux

Jusqu'à la fin des jours

La douceur de ses seins modelés par l'amour ${ }^{8}$

И если я останусь один

А она уйдёт

Я лишь сохраню

Сохраню навсегда

В своих ладонях

До конца дней

Нежность её грудей, слепленных самой любовью

Отметим двойную гиперболизацию планов героя, которая передаётся посредством эпитета «toujours» («навсегда») и собственно гиперболой «jusqu’à la fin des jours» («до конца дней») и которая показывает намерение оставить себе хотя бы одно воспоминание, если физическое присутствие возлюбленной станет невозможным.

Наряду с этим, влюблённый мужчина у Превера может быть и полигамен, как в стихотворении Sij'avais une soeur... (Если бы у меня бъла сестра...):

8 J. Prévert, Paroles..., op. cit., p. 195-196. 
Si j'avais une soeur

je t'aimerais mieux que ma soeur

Si j'avais tout l'or du monde

je le jetterais à tes pieds

Si j'avais un harem

tu serais ma favorite 9

Если бы у меня была сестра

я бы любил тебя больше, чем сестру

Если бы у меня было всё золото мира

я бы бросил его к твоим ногам

Если бы у меня был гарем

ты была бы моей любимой женой

Стихотворение построено на основе анафорического повтора «Si j’avais...» («Если бы у меня был(-a, -о)...») и серии глаголов в условном наклонении. Повторы в целом представляются значимыми для понимания текстов Превера, играя роль своего рода поэтического рефрена $^{10}$. В данном случае нас интересуют последние строки: «Si j’avais un harem / tu serais ma favorite» («Если бы у меня был гарем / ты была бы моей любимой женой»), которые противоречат предыдущим, где чувства героя представлены гиперболизированно. В последних же строках любимая женщина словно сравнивается с другими, и, хотя герой всё же готов сделать выбор в её пользу, отказываться от остального «гарема» он тоже не намерен.

Говоря о мужских персонажах, которые сами выступают в роли возлюбленных, можно отметить, что они отличаются склонностью скрываться, уходить, ускользать, сохраняя при этом власть над покинутыми (реально или в воображении) женщинами. Подтверждением этой мысли может служить фрагмент стихотворения C'est l'amour qui m'a faite (Меня сотворила любовь):

C'est l'amour qui m'a faite

L'amour qui m'a fait fête

L'amour qui m'a fait fée

Où donc est-il parti

L'amoureux que j'avais

\footnotetext{
9 J. Prévert, Fatras, Paris 2007, p. 123.

${ }^{10}$ Т. Балашова, «Игровая техника» сатирической инвективы: Жак Превер, https://mdeksperiment.org/post/20181217-igrovaya-tehnika [дата доступа: 20.04.2021].
} 
Qui me faisait plaisir

Qui me faisait rêver

Qui me faisait danser

Danser à sa baguette

C'était mon chef d'orchestre

Moi son corps de ballet ${ }^{11}$

Меня сотворила любовь

Любовь, которая подарила мне праздник

Любовь, которая сделала меня волшебницей

Куда же он ушёл?

Мой возлюбленный

Который доставлял мне удовольствие

О котором я мечтала

Для которого я танцевала

Танцевала под его дудку

Это был мой дирижёр

А я была его кордебалетом

В приведённом примере можно отметить сразу несколько показательных стилистических моментов. Во-первых, это анафорические повторы слова «l'amour» («любовь») и придаточного предложения «qui me faisait» («который доставлял мне...» либо, буквально «который заставлял меня...»), которые призваны показать зависимость героини от покинувшего её возлюбленного. Во-вторых, это анадиплосис «Qui me faisait danser / Danser à sa baguette» («Для которого я танцевала / Танцевала под его дудку»), который развеивает изначально позитивную коннотацию каузативной конструкции «Qui me faisait danser», превращая её, посредством метафоры «Danser à sa baguette», в иллюстрацию манипуляции, которой подвергалась героиня. Наконец, метафоры в последних строках примера «C'était mon chef d'orchestre / Moi son corps de ballet» («Это был мой дирижёр / А я была его кордебалетом») показывают вероятную вторичность героини для её возлюбленного, так как кордебалет - это ансамбль танцоров, исполняющих массовые номера, т.е., вполне возможно, в жизни героя была и «балерина-корифей», исполняющая сольные партии. При этом главная роль этого человека для героини эксплицитно показана за счёт метафоры «mon chef d'orchestre» («мой

${ }^{11}$ J. Prévert, Histoires et d'autres histoires, Paris 2012, p. 224-225. 
дирижёр»): очевидно, даже несмотря на расставание, он продолжает владеть её умом и сохраняет над ней определённую власть.

Потеря любимого также может провоцировать героинь Превера на самые драматические поступки, вплоть до самоубийства. В качестве примера мы можем привести стихотворение Adrien (Адриен), в котором шесть раз повторяются строки «Adrien ne fais pas la mauvaise tête! / Reviens!» («Адриен, не будь таким вредным! Вернись!»), причём они начинают стихотворение и завершают его, образуя кольцевую структуру. Между этими повторами мы встречаем перечисление всех странных действий, совершённых героиней во имя любви (как то: хранение на камине снежка, который Адриен когда-то в неё бросил, уход из дома на долгие годы, хранение в холодильнике трупа собаки, принадлежавшей Адриену). При этом о самом Адриене мы не знаем совершенно ничего: он фигурирует в тексте исключительно имплицитно, хотя и наделён именем (редкое явление в творчестве Превера, который практически не даёт имён своим героям), что придаёт ему дополнительную значимость. Квинтэссенцией экстраординарных проявлений героини становится самоубийство и последующее воскресение из мёртвых - и снова ради любви:

\author{
De la tour Saint-Jacques \\ je me suis jetée \\ avant-hier \\ je me suis tuée \\ à cause de toi \\ Hier on m'a enterrée \\ dans un très joli cimetière \\ et je pensais à toi \\ Et ce soir je suis revenue \\ dans l'appartement \\ où tu te promenais nu \\ du temps que j'étais vivante \\ et je t'attends... ${ }^{12}$ \\ С башни Сен-Жак \\ я бросилась \\ позавчера \\ и погибла \\ из-за тебя
}

${ }^{12}$ Ibidem, p. 119-120. 


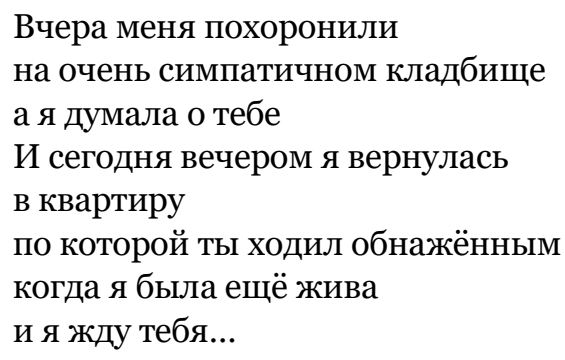

В приведённом выше примере мы видим серию действий в прошедшем времени, которые следуют непосредственно друг за другом; скорость их смены передаётся также временной триадой «позавчера - вчера - сегодня», которая перетекает в действие в настоящем времени: «et je t'attends - и я жду тебя». Характерно, что за этой формой настоящего времени следует многоточие, что свидетельствует о неограниченности этого действия во времени и о готовности героини ждать возвращения своего возлюбленного даже после смерти.

Ускользать от героини мужчина может и виртуально, в её воображении, как это показано в стихотворении Quand tu dors (Когда ты спишъ), где рефреном повторяются две строфы:

Toi tu dors la nuit
moi j’ai de l'insomnie
je te vois dormir
ça me fait souffrir ${ }^{13}$
Ты спишь ночью
а у меня бессонница
я смотрю, как ты спишь
и мне больно от этого

и

Toi tu rêves la nuit moi j’ai de l'insomnie je te vois rêver ça me fait pleurer ${ }^{14}$ 
Ты видишь сны по ночам

а у меня бессонница

я вижу, что тебе что-то снится

и плачу от этого

В двух приведённых примерах мы наблюдаем своего рода антитезу между «ты» и «я», где «ты» стоит на первом месте, но «я», тем не менее, представлено гораздо более развёрнуто. Если мужчина («ты») представлен глаголами, выражающими нейтральные либо положительные действия («dormir - спать», «rêver - видеть сны»), то состояние героини («я») показано глаголами и оборотами, обладающими негативным значением («avoir de l'insomnie - мучиться от бессонницы», «souffrir - страдать», «pleurer - плакать»). Причина столь подавленного настроения объясняется ниже:

Tes yeux fermés ton grand corps allongé

c'est drôle mais ça me fait pleurer

et soudain voilà que tu ris

tu ris aux éclats en dormant

où donc es-tu en ce moment

où donc es-tu parti vraiment

peut-être avec une autre femme

très loin dans un autre pays

et qu'avec elle c'est de moi que tu ris ${ }^{15}$

Твои глаза закрыты, твоё стройное тело лежит рядом

странно, но от этого я плачу

и вдруг ты смеёшься

заливисто смеёшься во сне

где же ты в это время?

где же ты на самом деле?

возможно, ты с другой

где-то очень далеко, в другом краю

и вместе с ней смеёшься надо мной

В данном примере мы видим ещё одну антитезу: глаголов «pleurer - плакать» и «rire - смеяться», причём глагол «rire» повторяется трижды, в том числе в сопровождении метафоры «аuх éclats - заливисто». Тревога героини из-за этого смеха, причина которого ей неведома, передаётся посредством анафорического

15 Ibidem, p. 115. 
повтора вопроса «où donc - где же», а также повтора эпитета «autre другой(-ая)», которые показывают ревность к воображаемой сопернице. В конечном итоге героиня находит решение, с помощью которого рассчитывает удержать ускользающего возлюбленного:

Toutes les nuits je pleure toute la nuit
et toi tu rêves et tu souris
mais cela ne peut plus durer
une nuit sûrement je te tuerai
tes rêves alors seront finis
et comme je me tuerai aussi
finie aussi mon insomnie
nos deux cadavres réunis
dormiront ensemble dans notre grand litt ${ }^{16}$

Каждую ночь я плачу ночь напролёт а ты видишь сны и улыбаешься но так дальше не может продолжаться однажды ночью я тебя точно убью тогда твои сны кончатся а поскольку я убью и себя кончится и моя бессонница наши два трупа

будут спать вместе в нашей широкой кровати

Мы видим повтор антитезы, передающей разность настроений героев и выраженной глаголами «pleurer - плакать» и «sourire улыбаться». Своеобразным синтезом этой антитезы становятся глаголы «tuer - убивать» и «finir - заканчиваться», где первый обладает выраженным негативным значением, а второй приобретает контекстуальное положительное значение, поскольку обозначает конец страданий героини. При этом, несмотря на столь масштабные и мрачные планы, днём героиня находится под не меньшим влиянием своего возлюбленного, чем ночью, о чём свидетельствуют следующие строки, уже из последней строфы стихотворения:

Voilà le jour et soudain tu t'éveilles

et c'est à moi que tu souris

tu souris avec le soleil

et je ne pense plus à la nuit ${ }^{17}$

${ }^{16}$ Ibidem, p. 116.

17 Ibidem, p. 117. 
И вот наступает утро, и внезапно ты просыпаешься

и улыбаешься мне

улыбаешься вместе с солнцем

и я болыше не думаю о том, что было ночью

Глагол «sourire - улыбаться», который ранее составлял антитезу слезам героини, употребляется в составе анадиплосиса и силлепсиса «et c'est à moi que tu souris / tu souris avec le soleil» («и улыбаешься мне / улыбаешься вместе с солнцем»), где также стоит отметить выделительный оборот «c'est à moi que tu souris - букв. ты улыбаешься именно мне»). Все вышеперечисленные стилистические приёмы показывают, что одной лишь улыбки возлюбленного достаточно, чтобы ночные страхи героини были забыты, - впрочем, вполне возможно, ночью они снова вернутся, поскольку в стихотворении делается акцент именно на регулярности её страданий.

\section{3. Нечеловеческие существа, наделённые мужскими качествами}

В текстах Превера можно встретить и персонифицированные нечеловеческие создания, которые приобретают мужские качества и мужскую манеру поведения. Так, в стихотворении Encore une fois sur le fleuve (Снова над рекой) солнце и ночь уподобляются, соответственно, мужчине и женщине, подтверждение чему можно найти в следующем примере:

Et encore une fois

le soleil se lève

le soleil libre et vagabond

qui aime à dormir au bord des rivières

sur la pierre

sous les ponts

Et comme la nuit au doux visage de lune

tente de s'esquiver

furtivement

le prodigieux clochard au réveil triomphant

le grand soleil paillard bon enfant et souriant 
plonge sa grande main chaude dans le décolleté de la

nuit

et d'un coup lui arrache sa belle robe du soir ${ }^{18}$

И снова

встаёт солнце

свободное солнце-странник

которое с удовольствием спит на берегах рек

на камне

под мостами

А когда прекрасная луноликая ночь

пытается улизнуть

тайком

этот невероятный бродяга, который просыпается победителем

это яркое, игривое, добродушное и улыбающееся солнце

запускает свою большую горячую руку в декольте

ночи

и резко срывает с неё нарядное вечернее платье

Характеристики солнца, которые встречаются в приведённом примере и выраженные эпитетами «libre - свободный», «vagabond странник», отчасти совпадают с репрезентацией персонажей-мужчин, которую мы рассматривали выше. Персонификация (и маскулинизация) солнца выражена напрямую посредством метафорических олицетворений «plonge sa grande main chaude dans le décolleté de la / nuit / et d'un coup lui arrache sa belle robe du soir» («запускает свою большую горячую руку в декольте / ночи / и резко срывает с неё нарядное вечернее платье»). Отметим, что в конце стихотворения показан момент заката, когда уже самому солнцу пора уходить, чтобы уступить место ночи. Здесь солнце репрезентировано уже посредством бестиарной метафоры, уподобляясь льву:

Ce grand lion rouge

c'est le Soleil

qui traîne encore un peu avant de s'en aller

(...)

Et c'est pour cela qu'il fait la gueule

et qu'il n'est pas content

et qu'il secoue en rugissant

sa grande crinière crépusculaire

sur les passants

18 Ibidem, p. 9. 


\section{(...)}

Alors le grand lion rouge se marre

et il se fout d'eux

et il caresse en s'en allant

de sa grande patte rousse

nonchalamment

les reins et les fesses d'une femme

qui s'arrête brusquement

songeant à son amant

et regarde la Seine en frissonnant ${ }^{19}$

Этот большой красный лев -

это солнце

которое тянет время ещё немного, прежде чем уйти

(...)

Поэтому он и злится

он недоволен

и он рычит, встряхивая

своей густой сумеречной гривой

над головами прохожих

(...)

И тогда большой красный лев хохочет

и насмехается над ними

и, уходя, гладит

своей большой рыжей лапой небрежно

талию и ягодицы какой-то женщины

которая резко останавливается

задумавшись о своём любовнике

и, слегка дрожа, смотрит на Сену.

В данном примере акцент делается, в первую очередь, на бестиарной репрезентации солнца как льва, о чём свидетельствуют метафоры «et qu'il secoue en rugissant / sa grande crinière crépusculaire» («и он рычит, встряхивая / своей густой сумеречной гривой») и «sa grande patte rousse» («его большая рыжая лапа»). Тем не менее, метафорический глагол «caresser» («гладить») в сочетании с упоминанием женского тела, уподобляет солнце, хоть и в львином обличье, мужчине, причём настроенному довольно игриво.

Земными, мужскими чертами могут наделяться и ангелы - как, например, в стихотворении Le paradis marin (Рай морской):

19 Ibidem, p. 28-29. 
...et

$\mathrm{EVE}^{20}$ vécut avec un

ANGE dans une

ILE

...et

l'habit bleu de l'ange

fut jeté aux orties. ${ }^{21}$

‥и

Ева стала жить

С ангелом

На острове

...и

синее одеяние ангела

было забыто.

Маскулинизация ангела в данном примере имплицитна и показана посредством глагола «vivre» («жить, сожительствовать»), a также силлепсиса «et / l'habit bleu de l'ange / fut jeté aux orties» («и / синее одеяние ангела / было забыто (буквально - «брошено в крапиву»): последний показывает как отречение ангела от своей небесной природы (так как синее одеяние считается атрибутом ангелов-хранителей ${ }^{22}$ ), так и в буквальном значении обнажение перед искусительницей. Характерно, что три строки стихотворения образуют акроним «Évangile» - «Евангелие», что также может выступать как аллюзия на антиклерикализм Превера и на ироническое отношение к религии.

Подводя итог, мы можем констатировать, что мужские персонажи в творчестве Жака Превера могут выступать в разных ипостасях, основные из которых - отец, влюблённый / любимый мужчина, нечеловеческое существо, наделённое мужскими чертами. Фигура отца у Превера зачастую обесценивается и может подвергаться как моральному унижению, так и физическому уничтожению, причём от руки своего же потомства. Ключевыми языковыми средствами в репрезентации этой категории персонажей являются перифразы, антифразисы, парадоксы. Что касается мужчины влюблённого или любимого, то в этой группе персонажей мы можем выделить две

\footnotetext{
20 Здесь и далее графическое оформление текста соответствует оригиналу.

${ }^{21}$ J. Prévert, Fatras, Paris 2007, p. 125.

22 https://www.wemystic.fr/ange-gardien-vertus/ [дата доступа: 10.11.2020].
} 
тенденции. Влюблённый мужчина показан как своего рода тюремщик для той, кого он любит, но возлюбленная от него либо ускользает, либо он сам готов её отпустить. Наряду с этим, влюблённый герой у Превера может проявлять и склонность к полигамии. Основными лингвостилистическими средствами, которые описывают этих персонажей, можно считать метафоры, гиперболы, парадоксы, а также семантически значимые сочетания глаголов в утвердительной и отрицательной формах. Любимый же мужчина сам склонен ускользать и оставаться загадкой, зачастую провоцируя влюблённую в него героиню на весьма своеобразные поступки. Эта группа персонажей показана посредством метафор, антитез, повторов (в частности, анафор и анадиплосисов). Наконец, третья ипостась мужских персонажей в творчестве Превера - это нечеловеческие существа, обладающие мужскими характеристиками и мужской манерой поведения, как, например, солнце (которое сначала срывает платье с ночи, а затем поглаживает прохожую на набережной) или ангел (который вступает в любовную связь с Евой). Наиболее значимыми фигурами при изображении данной группы персонажей выступают персонификации, а также силлепсисы и метафоры.

\section{Литература}

Ange gardien: les vertus, https://www.wemystic.fr/ange-gardien-vertus/ [дата доступа: 10.11.2020].

Prévert J., Choses et autres, Paris 2011.

Prévert J., Fatras, Paris 2007.

Prévert J., Histoires et d'autres histoires, Paris 2012.

Prévert J., La pluie et le beau temps, Paris 2011.

Prévert J., Paroles, Paris 2011.

Балашова Т., «Игровая техника» сатирической инвективы: Жак Превер, https://md-eksperiment.org/post/20181217-igrovaya-tehnika [дата доступа: 20.04.2021].

Лотман Ю., Риторика, [в:] Статьи по семиотике и топологии культуры, https://www.gumer.info/bibliotek_Buks/Culture/Lotm/index.php [дата доступа: 01.11.2020].

Хмельницкая Т., Жак Превер (род. в 1900 г.). Кровь и птицы, http://17v-eurolit.niv.ru/17v-euro-lit/pisateli-francii/zhak-prever.htm [дата доступа: 21.04.2021]. 


\section{References}

Ange gardien: les vertus, https://www.wemystic.fr/ange-gardien-vertus/ [дата доступа: 10.11.2020].

Balashova T., «Igrovaya tekhnika» satiricheskoj invektivy: ZHak Prever, https://md-eksperiment.org/post/20181217-igrovaya-tehnika [data dostupa: 20.04.2021].

Lotman YU., Ritorika, [v:] Stat'i po semiotike $i$ topologii kul'tury, https://www.gumer.info/bibliotek_Buks/Culture/Lotm/index.php [data dostupa: 01.11.2020].

KHmel'nitskaya T., ZHak Prever (rod. $v 1900$ g.). Krov' i ptitsy, http://17v-eurolit.niv.ru/17v-euro-lit/pisateli-francii/zhak-prever.htm [data dostupa: 21.04.2021].

Prévert J., Choses et autres, Paris 2011.

Prévert J., Fatras, Paris 2007.

Prévert J., Histoires et d'autres histoires, Paris 2012.

Prévert J., La pluie et le beau temps, Paris 2011.

Prévert J., Paroles, Paris 2011. 